\title{
Physico-chemical and sensory properties of functional confectionery products with Rosa Canina powder
}

\author{
Violina Popovici ${ }^{1}$, Oxana Radu ${ }^{1}$, Viacheslav Hubenia ${ }^{2}$, \\ Eugenia Covaliov $^{1}$, Tatiana Capcanari $^{1}$, Cristina Popovici ${ }^{1}$
}

\author{
1 - Technical University of Moldova, Faculty of Food Technology, Chisinau, \\ Republic of Moldova \\ 2 - National University of Food Technologies, Kyiv, Ukraine
}

\section{Keywords: \\ Rosehip \\ Confectionery \\ Candies \\ Functionality}

Article history:

Received

30.01.2019

Received in revised

form 17.05.2019

Accepted

28.11.2019

Corresponding

author:

Cristina Popovici

E-mail:

cristina.popovici@

toap.utm.md

DOI:

$10.24263 / 2304-$

974X-2019-8-4-12

\section{Abstract}

Introduction. The purpose of research was to evaluate the physico-chemical and sensory paramenters of functional confectionery products with rosehip powder.

Material and methods. In research Rosa Canina harvested in the Republic of Moldova (Central region) was analized. Physico-chemical methods and sensory evaluation of the elaborated functional confectionery products and DPPH antioxidant activity of the roseship extract were used.

Results and discusisions. It was established that rosehip powder can be used as an antioxidant and natural colorant in the preparation of BIO candies enriched with vitamins, natural antioxidants. The acidity index of this products in camparison with the control sample it is within the permissible limits $0,12 \pm$ $0,01 \%$, and the high content of caratenoids gives the products the red-orange color, so the rosehip powder can be used to obtain functional products. The elaborated functional candies are characterized by positively rated sensory and physico-chemical indices, the value of the acidity index constituting $1.15 \pm 0.01 \mathrm{mg}$ $\mathrm{KOH} / \mathrm{l}$ and the humidity mass fraction of $24.19 \pm 0.01 \%$. The results showed that higher concentration of rosehip powder give orange color and the acid value of the product increases, which represent a disadvantage of the rosehip extract, this provides the opportunity to open a new research direction. From a sensory point of view, the product with small content of rosehip power was positively appreciated, which confirms that food products based on natural dye of plan origin is a good alternative for obtaining safe and natural products for consumer health. A relevant aspect of this paper is the fact that an additive and natural dye extracted from the rosehip fruits was obtained. According to the recipe, the obtained natural additive has replaced the synthetic one, giving the prepared candies a pleasant taste and a specific smell of rosehip flowers.

Conclusion. It is justified functional properties and high quality of the confectionery products in which the synthetic food additives were replaced with the natural dyes extracted from plant products. 


\section{Introduction}

Rosehip or Wild Rose (Rosa Canina) is a shrub of the Rosaceae family. It includes over 400 species, widespread in temperate and subtropical areas. Physico-chemical composition, amount of vitamins, pigments etc. of rosehip fruits depends on the climatic conditions, also varying according to the species and the intensity of their growth. The most valuable part of the fruit is the outer shell, which makes up 54-87\% of the total mass.

Carotenoid intake with $\beta$-carotene, lycopene and rubixantine isomers, as protavitamin $\mathrm{A}$, is one of the main strengths of rosehip fruit. In addition, vitamins B1, B2, B3, B5, K, P, $\mathrm{PP}, \alpha^{\alpha}-, \beta$-tocopherol (vitamin E), nicotinic acid are found. A specific feature of rosehip fruit is the lack of the ascorbinase enzyme, which destroys vitamin $\mathrm{C}$ [1]. Fresh rosehip fruits contain vitamin $\mathrm{C}-4,000 \mathrm{mg} / \%$, bioflavonoids up to $3,500 \mathrm{mg} / \%$, carotene from 3 to $8 \mathrm{mg} / \%$, folic acid up to $0.88 \mathrm{mg} / \%$, tocopherols up to $0,69 \mathrm{mg} / \%$. Polyphenolic compounds of rosehip are represented by catechins, leicoanthocyanins, anthocyanins, flavonols. The content of catechins in most species is $856-2712 \mathrm{mg} \%$, of leicoanthocyanins of 72-1296 $\mathrm{mg} \%$. The sum of these two polyphenols correlates with the sum of the dyes and tannins content [2]. The rosehip fruits are also a powerful mineralizer, containing magnesium $(\mathrm{Mg})$, calcium $(\mathrm{Ca})$, iron $(\mathrm{Fe})$, manganese $(\mathrm{Mn})$, phosphorus $(\mathrm{P})$, potassium $(\mathrm{K})$, selenium $(\mathrm{Se})$, sulfur $(\mathrm{S})$. ), zinc $(\mathrm{Zn})$. Also important is their content of polyphenols, anthocyanins, pectin, citrates, malic acid and citric acid, terpenoids and glycosides [3]. Fruit sugar is sucrose, invert sugars (glucose and fructose). At maturity the fruits contain a larger quantity of starch, which in the phase of ripening turns into sugar. In addition, in the pulp, there are fibers and pentosanes. Of the organic acids, the rosehip fruits contain only citric acid. The fruits are relatively rich in pectic substances.

The administration in the pastry products of a small dose of dried rosehip powder (0.5$1.0 \%$ ) has a positive influence on the physico-chemical and sensory properties of the pastry products. The administration of rose-hip increases the solubility of iron in foods up to 0.3 $0.35 \mathrm{mg} \mathrm{Fe} / 100 \mathrm{~g}$ product [5].

Rosehip powder presents an organic product, which is a source of concentrated active ingredients and improves the nutritional and sensory properties of manufactured products. This product has a good reducing capacity and can be used in the manufacture of pastry products as an ingredient to give the dough color, taste and aroma, as well as fillings.

One of the components used in the production of functional foods is the rosehip powder that contributes to the vitaminization and increasing the resistance of the body. Due to the high concentration of caratenoids it is used as a natural dye giving the products red-orange color [3].

The antioxidant properties of the rosehip processing product are known, which positively affect the shelf life of confectionery [15].

The research topic addressed is quite current because the confectionery products require a substantial correction of their chemical composition in the direction of increasing the content of vitamins, minerals and food fibers, reducing the energy value and enriching the products with functional ingredients $[4,16]$. The reason for choosing this subject was that the preparation of functional candies with the addition of rosehip powder is a new technology, opting to replace synthetic food additives with BIO products $\lceil 5,17\rceil$.

The aim of the research was to evaluate the physico-chemical and sensory characteristics of the new functional product. In order to achieve the goal, the obiectives were pursued: (1) the analysis of the global trends in the production of functional candies by studying, analyzing and systematizing the scientific literature and the patents of invention; (2) justification for choosing rosehip powder as a natural colorant; (3) determining the content of polyphenols, caratenoids and the acidity index of rosehip extract; (4) analysis of the results of scientific research. 


\section{Materials and methods}

\section{Materials}

The collection of berries is a first step in preparing the raw materials needed to carry out the established research. The fruits of rosehip were harvested in quantities of $3-5 \mathrm{~kg}$ and then subjected to the convection drying process for a period of about 6 hours. The dried fruits were finely ground and sifted until an extra-fine powder was obtained. Experimental samples of dried rosehip fruits and powder used in the work are presented in Figures 1 and 2.

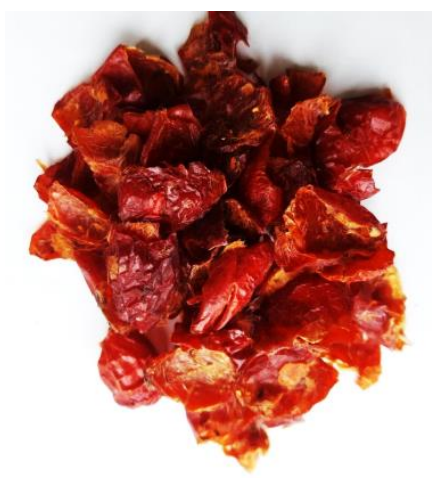

Figure 1. Dried rosehip fruits

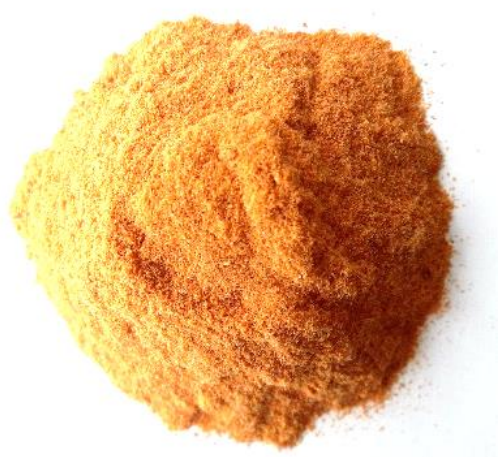

Figure 2. Rosehip powder

\section{powder \\ Functional product preparation technology - BIO candies with added rosehip}

The functional candy production technology has a number of features, but the basis is a single scheme that includes the following steps: (1) preparing the raw materials for production, (2) preparing the mixtures, (3) preparing the composition, (4) cooling the composition, (5) processing and forming of candies, (6) packaging them. In the process of developing functional candy production technology, it is necessary to develop techniques for processing raw materials and semi-finished products, in which minimal chemical changes of nutrients (isomalt, dietary fibers and proteins) are guaranteed, the optimal structural and mechanical properties of semi-finished and finished products.

\section{Physico-chemical methods of analysis}

Determination of the dry matter. The sample taken for determination is exposed to a source of heat up to a constant weight. Weight loss, calculated as a percentage, represents the moisture content, and the remaining residue - the dry matter [6]. The dry matter content $(\mathrm{X}, \%)$ in the analyzed sample is calculated using the following formula:

$$
X=\frac{\left(\mathrm{m}_{2}-\mathrm{m}\right)}{\left(\mathrm{m}_{1}-\mathrm{m}\right)} \cdot 100 \%,
$$

where: $m-$ mass of the vial with the glass rod and sand, $g$;

$\mathrm{m}_{1-}$ mass of the vial with the glass rod and sand + the product before drying, $\mathrm{g}$;

$\mathrm{m}_{2}$ - the mass of the vial with the glass rod and sand after drying, $\mathrm{g}$. 
Antioxidant activity determination using free radical DPPH. Determination of the antioxidant activity of the lipophilic extracts was performed using LLG uniSPEC -2 spectrophotometer and expressed as a\% inhibition of DPPH using the following equation [7]:

where:

$$
\mathrm{AA} \%=\frac{\mathrm{A}_{0}-\mathrm{A}_{\mathrm{t}}}{\mathrm{A}_{0}} \cdot 100 \%
$$

A0 - absorbance of the DPPH solution at $\mathrm{t}=0 \mathrm{~s}$;

At - absorbance of the DPPH solution after $30 \mathrm{~min}$;

A lower value of At in the analyzed sample shows a higher antioxidant activity.

Determination of the total polyphenols content. Determination of total polyphenols content was performed according to Sturza (2016) on the same spectrophotometer, at $K=765$ $\mathrm{nm}$, using a $10 \mathrm{~mm}$ quartz cuvette $[6,8]$. The results of the total polyphenols content, expressed in mg GA / $100 \mathrm{~g}$ of vegetal material, were obtained using the gallic acid calibration curve $(\mathrm{y}=1.4 \mathrm{x}+0.0037, \mathrm{R} 2=0.999)$.

Determination of the total content of assimilating pigments (chlorophyll a, chlorophyll b, total carotenoids). For the determination of the content of assimilating pigments, was measured the absorbance at wavelengths of $663 \mathrm{~nm}$ for chlorophyll a, $647 \mathrm{~nm}$ for chlorophyll $\mathrm{b}$ and $470 \mathrm{~nm}$ for total carotenoids, to $10 \mathrm{ml}$ of extract versus the deodorized refined oil (blank). The carotenoid content were determined by the following equations [912]:

where:

$$
\begin{gathered}
\mathrm{C}_{\mathrm{a}}\left(\mathrm{mgL}^{-1}\right)=\left(12,25 \times \mathrm{A}_{663.2}\right)-\left(2,79 \times \mathrm{A}_{646.8}\right) \\
\mathrm{C}_{\mathrm{b}}\left(\mathrm{mgL}^{-1}\right)=\left(21,5 \times \mathrm{A}_{646.8}\right)-\left(5,1 \times \mathrm{A}_{663.2}\right) \\
\mathrm{C}_{\mathrm{a}+\mathrm{b}}\left(\mathrm{mgL}^{-1}\right)=\frac{\left(1000 \times \mathrm{A}_{470}-1.82 \times \mathrm{C}_{\mathrm{a}}-85.02 \times \mathrm{C}_{\mathrm{b}}\right)}{198}
\end{gathered}
$$

$\mathrm{A}_{663.2}$ - solution absorbance at $\lambda=663.2 \mathrm{~nm}$;

$\mathrm{A}_{646,8}$ - solution absorbance at $\lambda=646.8 \mathrm{~nm}$;

$\mathrm{A}_{470}$ - solution absorbance at $\lambda=470 \mathrm{~nm}$;

Determination of antioxidant capacity - HPSA. For the determination of HPSA, in the titration flasks, $1 \mathrm{ml}$ of sample was mixed with $1 \mathrm{ml}$ of hydrogen peroxide solution $\mathrm{H}_{2} \mathrm{O}_{2}(0.1 \mathrm{mM})$. Then 2 drops of ammonium molybdate, $10 \mathrm{ml}$ of $\mathrm{H} 2 \mathrm{SO} 4$ (2M) sulfuric acid and $7 \mathrm{ml}$ of KI potassium iodide $(1.8 \mathrm{M})$ were added. The obtained solution was titrated with sodium thiosulfate $\mathrm{N} 2 \mathrm{~S} 2 \mathrm{O} 3(5.09 \mathrm{mM})$ until the yellow colour disappeared. The volume (V1) of sodium thiosulfate $\mathrm{Na} 2 \mathrm{~S} 2 \mathrm{O} 3(5.09 \mathrm{mM})$ used for titration was recorded.

where:

$$
\% \mathrm{H}_{2} \mathrm{O}_{2}=\frac{V_{0}-V_{1}}{V_{0}} \cdot 100 \%
$$

$\mathrm{V}_{0}$ - volume of sodium thiosulphate $\mathrm{N}_{2} \mathrm{~S}_{2} \mathrm{O}_{3}(5,09 \mathrm{mM})$ spent for titration of the control sample in the presence of hydrogen peroxide (without sample);

$\mathrm{V}_{1}$ - volume of sodium thiosulphate $\mathrm{N}_{2} \mathrm{~S}_{2} \mathrm{O}_{3}(5,09 \mathrm{mM})(5.09 \mathrm{mM})$ spent for titration of the sample in the presence of hydrogen peroxide. 
Determination of acid value (AV). Determination of AV was performed by the volumetric method and the results obtained were calculated according to the following equation [13]:

where:

$$
\mathrm{AV}=\frac{\mathrm{V}_{\mathrm{KOH}} \cdot \mathrm{N}_{\mathrm{KOH}} \cdot 5.611}{\mathrm{~m}},[\mathrm{mg} \mathrm{KOH} / \mathrm{g}]
$$

$\mathrm{V}_{\mathrm{KOH}}-$ volume of the potassium hydroxide, [ml];

$\mathrm{N}_{\mathrm{KOH}}-$ concentration of the potassium hydroxide, $\left[\mathrm{mol} / \mathrm{dm}^{3}\right]$;

$\mathrm{m}$ - mass of the sample, $\mathrm{g}$.

Gastrointestinal in vitro digestion. The samples were weighed $10 \mathrm{~g}$ of product and dissolved in $100 \mathrm{ml}$ of $\mathrm{HCl}$ solution with $\mathrm{pH}=1.5-2.0,15 \mathrm{mg}$ pepsin was added. At the same time, similar samples of $10 \mathrm{~g}$ of product where dissolved in $100 \mathrm{ml} \mathrm{NaHCO}_{3}$ solution with $\mathrm{pH}=8.2,15 \mathrm{mg}$ trypsin was added. The samples were thermostated at $37 \pm 0.1{ }^{\circ} \mathrm{C}$ by continuous stirring at $95 \mathrm{rpm}$ for 60 minutes. From the initial samples $(0$ minutes of thermostat) as well as after 60 minutes, 120 minutes and 180 minutes, respectively, aliquots were taken in order to spectrophotometrically determine the antioxidant activity using the free radical DPPH. Each aliquot was centrifuged for $10 \mathrm{~min}(6000 \mathrm{rpm})$, then the filtrate (1 $\mathrm{ml}$ each) was subjected to the analysis. The direct reaction was determined by the antioxidant activity of the aliquots: $3.9 \mathrm{ml}$ of DPPH solution and $0.1 \mathrm{ml}$ of the analyzed sample were introduced. As a reference sample, methanol was used. The reaction took place for $30 \mathrm{~min}$ in a dark place. During this time the absorbance was read at the spectrophotometer "LLG uniSPEC -2" [14].

Sensory evaluation. The functional food products were determined by a sensory panel of 10 members. They rated the samples for appearance, aroma, taste, and overall acceptability by using a five-point Hedonic scale (5 and 1 representing "like extremely" and "dislike extremely" respectively) [10].

Statistical analysis. Variance analysis of the results was carried out by least square method with application of Microsoft Office Excel program. Differences were considered statistically significant if probability was greater than 95\% (q < 5\%). All assays were performed at room temperature, $20 \pm 1^{\circ} \mathrm{C}$. Experimental results are represented according to standard rules.

\section{Results and discussions}

\section{Physico-chemical and antioxidant properties of rosehip powder}

The physical-chemical characteristics of a product have an essential role in the evaluation of its food quality and safety. In this regard, several indexes have been determined in order to analize qualitatively the investigated horticultural raw material.

According to the data from Table 1, the low value of the water weight fraction of rosehip powder, $5.20 \pm 0.01 \%$, was established. This fact argues for the possibility of preserving the rosehip powder for a long time and using it for other products elaboration [3]. 
Physico-chemical properties of rosehip powder

\begin{tabular}{|c|l|c|}
\hline $\mathbf{N r}$ & \multicolumn{1}{|c|}{ Parameter } & Value,\% \\
\hline 1 & Weight fraction of water,\% & $5.20 \pm 0.01$ \\
\hline 2 & Acid Value, mg KOH/l & $0.12 \pm 0.01$ \\
\hline 3 & Antioxidant activity,\% HPSA & $16.5 \pm 1.2$ \\
\hline 4 & Polyphenols content, mg AG/100 g plant & $1981.28 \pm 3.57$ \\
\hline
\end{tabular}

The composition of food products contains acidic substances that cause an acid reaction to them [6]. Acidic substances can be present in raw materials, as well as formed while technological processes or during storage [5]. Acidity is an important property for the appreciation of food quality, because it directly contributes to the taste formation and is used as the indicator of some products freshness [12]. Following the determination of the acidity index of analyzed rosehip extract, it was showed that the obtained value, $0.12 \pm 0.01 \mathrm{mg}$ $\mathrm{KOH} / \mathrm{l}$, did not exceed the maximum permissible limits [6]. This fact encouraged us to use the rosehip powder in new functional products obtaining [4].

The dried and ground fruits were mixed with a deodorized refined oil in the ratio 1:15 and with 50\% ethyl alcohol in the ratio 1:10 to obtain liposoluble and hydroalcoholic extracts. The obtained compositions were stirred for 3 hours at $37^{\circ} \mathrm{C}$.

The extracts were separated by centrifugation at $7000 \mathrm{rpm}$ for 10 minutes, stored in dark-colored glass vials and kept in the refrigerator $\left(\mathrm{t}= \pm 4{ }^{\circ} \mathrm{C}\right)$.

Hydrogen Peroxide Scavenging Activity (HPSA) reflects the level of system resistance against oxidative deradation, caused by the presence of free oxygen - the main oxidizing agent, regardless of how oxidation reactions are initiated [9]. In the case of analyzed rosehip extract, HPSA is $16.5 \pm 1.2 \%$, which positively argues for the possibility of synthetic additives substitution with natural antioxidants obtained from horticultural sources such as rosehip fruits.

Polyphenols are biologically active compounds that exhibit antioxidant character by the inhibition of free radicals and the deceleration of oxidative and alteration processes in food products [7]. The determination of extracts polyphenol content was performed using the Folin-Ciocalteu reagent by spectrophotometric methods. The obtained data showed that the polyphenol content was $1981.28 \pm 3.57 \mathrm{mg} \mathrm{GA} / 100 \mathrm{~g}$ plant.

Carotenoids take part of the compounds class that is characterized by coloring capacity, beneficial health and anti-obesity effects [10]. Carotenoids are also widely used in many industrial fields, such as the foods, pharmaceuticals and cosmetics [11].

It was established [1-3] that carotenoid content could vary between 1 and $20 \mathrm{mg} / \mathrm{L}$ depending on the region of cultivation, season and climatic conditions in the region. The content of $\alpha$ and $\beta$ chlorophyll, $\beta$-carotene, lycopene and zeaxanthin in the liposoluble extract of analyzed rosehip was determined spectrophotometrically (Figure 3 ). 


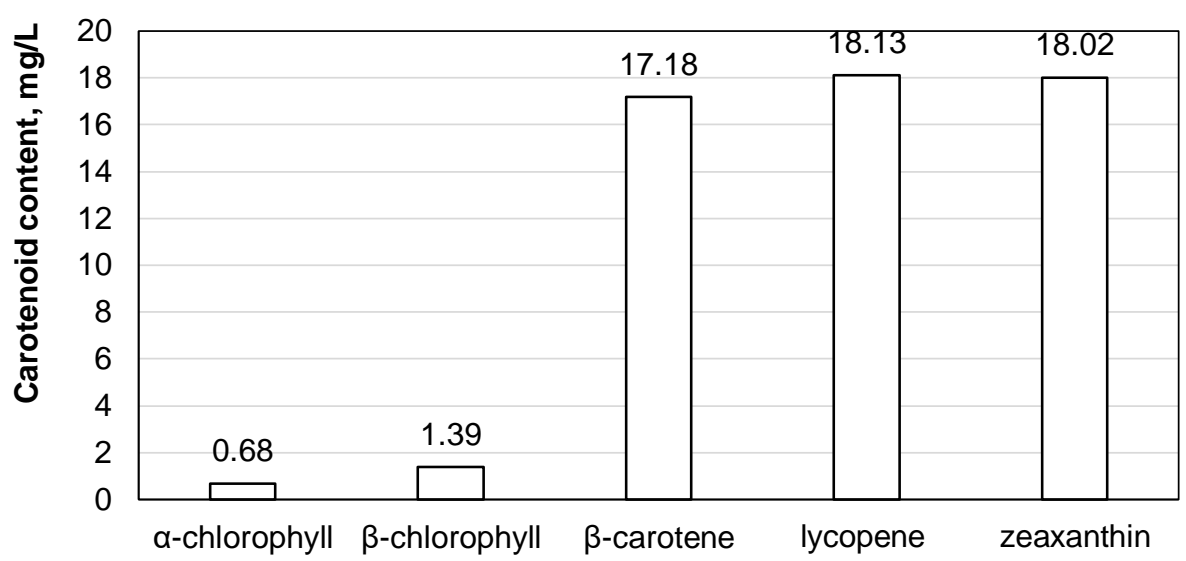

Figure 3. Carotenoid content in obtained rosehip extracts

According to Figure 3, the analyzed rosehip extract is characterized by a high carotenoid content. Generally, carotene are orange pigments - red to yellow. In this respect, the following results were obtained: $17.18 \pm 0.01 \mathrm{mg} / \mathrm{L} \beta$-carotene; $18.13 \pm 0.03 \mathrm{mg} / \mathrm{L}$ lycopene; $18.02 \pm 0.02 \mathrm{mg} / \mathrm{L}$ zeaxanthin. It was also showed the presence of chlorophyll - the group of green pigments from plants and other photosynthetic organisms: $0.68 \pm 0.01 \mathrm{mg} / \mathrm{L} \alpha-$ chlorophyll and $1.39 \pm 0.02 \mathrm{mg} / \mathrm{L} \beta$-chlorophyll.

Antioxidants are substances that slow down or stop the harmful action of oxidants [7]. The main characteristic of antioxidant substances is the ability to capture free radicals [8]. Phenolic compounds, polyphenols, carotenoids, flavonoids are antioxidant compounds that inhibit free radicals (peroxides, hydroperoxides) and respectively inhibit the mechanism of oxidation itself [12]. Forest berries, especially rosehip, are considered very rich in antioxidant compounds.

The analysis of the antioxidant activity was performed using the free radical DPPH in order to estimate the antioxidant potential of studied rosehip extracts (Figure 4).

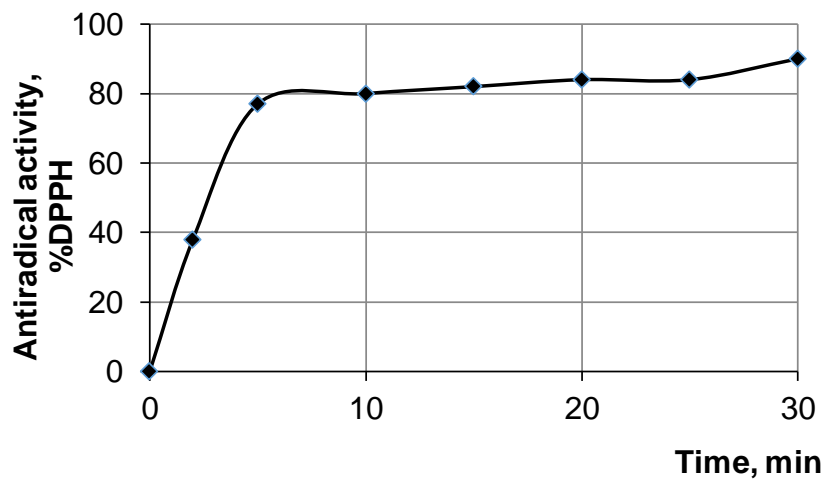

Figure 4. The antioxidant activity of rosehip lipidic extract 
It has been established that rosehip powder is characterized by a high antioxidant capacity, because the value of DPPH free radical inhibition capacity after a 30-minute action period constitutes $90.84 \pm 0.86 \%$. This fact is explained by the rich content of biologically active compounds with antioxidant character in the analyzed extract and, respectively, in the rosehip powder [2].

\section{Bioavailability of biologically active compounds according to in Vitro simulation of gastrointestinal digestion}

The bioavailability of biologically active compounds is the ratio of the amount of active substance to the rate at which it is transferred, absorbed into the body, reaches the site of action and manifests its biological effect [14]. Numerous researches [1, 2, 7, 8, 9] have been carried out regarding the content of biologically active substances with antioxidant character in fruits, fruit extracts, etc. The digestion process directly influences the composition of the extracts depending on the conditions under which the physiological digestion processes and the multitude of processes that take place in the gastrointestinal tract are performed. In order to study the evolution of the antioxidant activity of functional products with the addition of rosehip powder, the simulation of gastric and intestinal digestion over time was performed (Figures 5 and 6).

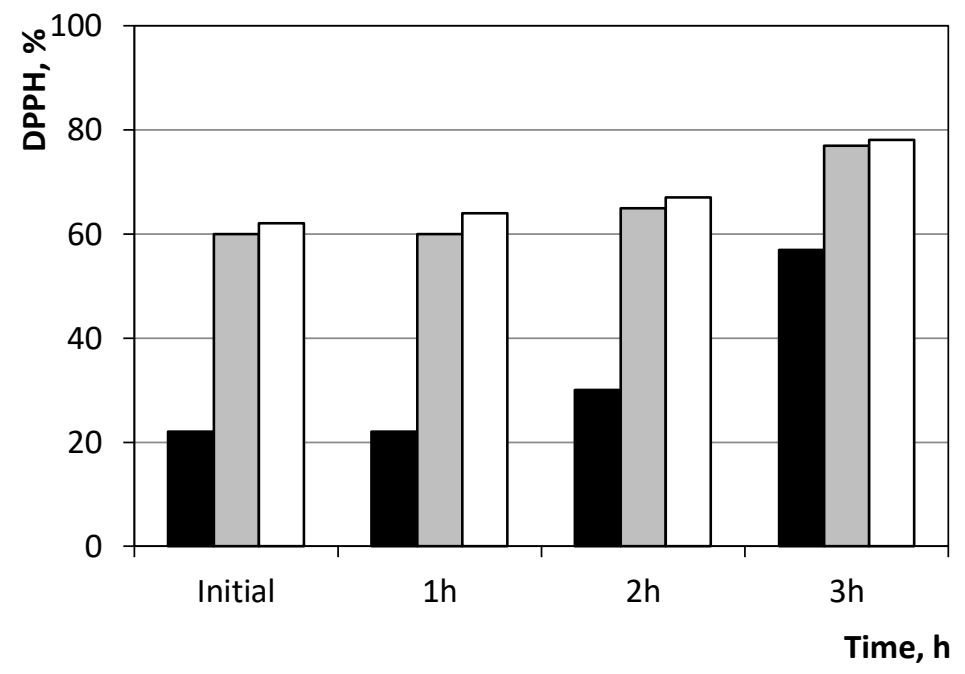

- Control sample $\quad \square$ rosehip $5 \% \quad \square$ rosehip $10 \%$

Figure 5. Bioavailability of biologically active compounds in acidic medium (gastric digestion)

In consonance with data obtained by the induced gastric digestion (acidic medium), the samples with rosehip addition show an essential increase of antioxidant activity in comparison with the control samples, for which values vary between 24.38 and $53.57 \%$. These values range within $60.36-72.75 \%$ for the samples with 5\% rosehip and within 65.80 $77.85 \%$ for the samples with $10 \%$ rosehip, respectively. 
The sequential increase of antioxidant activity over 3 hours is explained by the gradual release of biologically active compounds in the digestion process. The important factor refers to the influence of solution $\mathrm{pH}$ and enzymatic interactions in the investigated product. It has been shown that the increased polyphenol content enhance the antioxidant capacity of the obtained samples. The essential activity deviation of the samples with the addition of rosehip powder in comparison with the control samples can be also explained by the presence of other substances that increase the antioxidant capacity of the product as a result of in Vitro digestion processes. These biologically active compounds such as amino acids, peptides are released during digestion and undergo modifications that can subsequently affect the ability of free radicals inhibition. The another hypothesis consists in the loss of volatile substances during gastric digestion due to the increased antioxidant capacity of the product.

The obtained data show that gastric digestion doesn`t essentially change the qualitative and quantitative composition of biologically active compounds with antioxidant character in the analyzed product. This fact suggests that these compounds have high stability in the conditions of low $\mathrm{pH}$. Both the acidic medium and digestive enzymes favor the release of biologically active compounds, that respectively influence positively on the antioxidant capacity of the products based on rosehip powder [14].

Simultaneously with the analysis of gastric digestion processes, the simulation of the intestinal digestion phase was carried out by the samples incubation in alkaline medium $(\mathrm{pH}$ $=8.2$ ), determining the product antioxidant activity over a 3 -hour period (Figure 6).

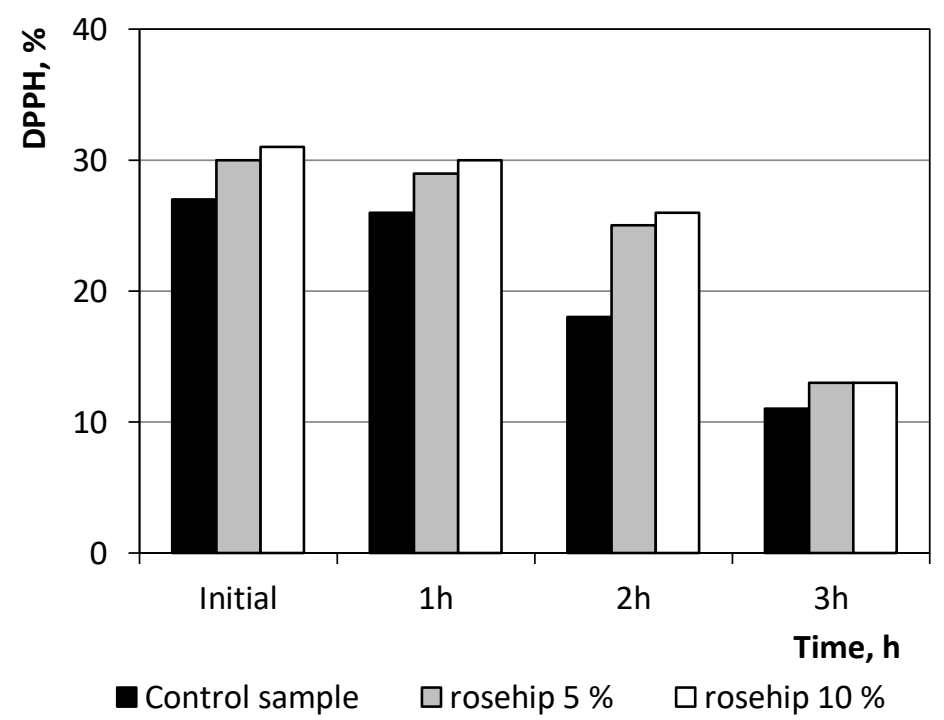

Figure 6. Bioavailability of biologically active compounds in alkaline medium (intestinal digestion)

The obtained data show that the antioxidant activity of samples based on rosehip powder, both $5 \%$ and $10 \%$ samples, is higher compared to the control sample and vary within $31.21-14.32 \%$ and $29.72-13.11 \%$, respectively. Whereas the values of the control samples vary within $26.38-10.95 \%$. 
The gradual decrease of the antioxidant activity within 3 hours both for the samples with rosehip addition and for the control samples was established while the intestinal digestion simulation. This fact can be explained by the low stability of biologically active compounds under alkaline conditions $(\mathrm{pH}=8.2)$ and the formation of metabolites that inhibit the antioxidant activity of biologically active compounds in the investigated products.

\section{powder \\ Weight fraction of water and acidity index of functional products with the rosehip}

The weight fraction of water for the control samples as well as the samples with Rosehip (5 and 10\%) are within the allowable limits $(30.0 \%)$ for candies on the base of dried fruit. In the case of samples with the rosehip, the weight fraction of water shows a slight decrease, which ensures a higher degree of stability compared to the control sample.

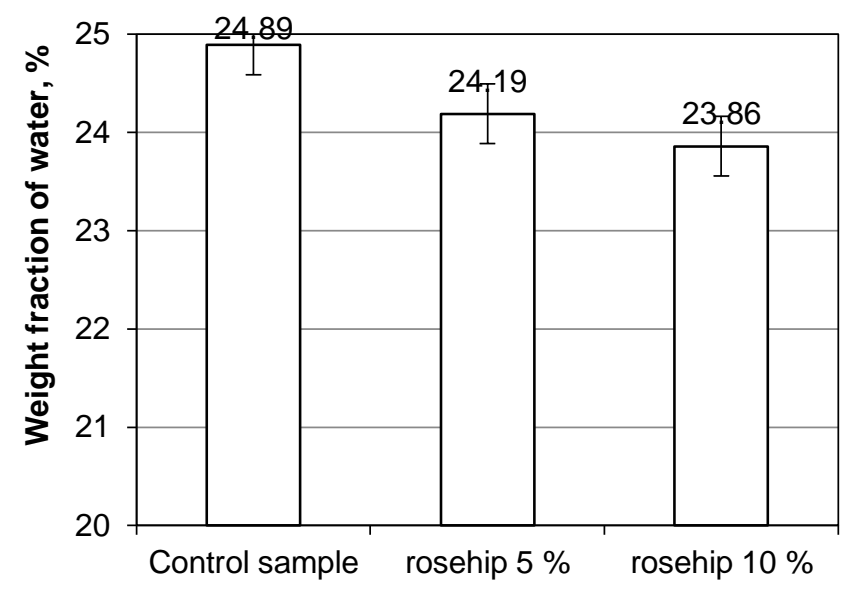

Figure 7. Weight fraction of water in functional candies with the rosehip powder, $\%$

Acidic substances may come from raw materials, technological processes or may be formed during storage [13]. Acidity is an important property in the appreciation of the quality of the food products as it directly contributes to the formation of the taste and for some products it is an indicator of their freshness [4].

The acidity index of the control sample is $1.14 \pm 0.01$, and in the case of samples with of 5 and $10 \%$ rosehip, it values $1.15 \pm 0.01$ acidity grade and $1.17 \pm 0.01$ acidity grade respectively. The obtained values are within the maximum permissible limits $(A=4.0$ max. acidity grade), which encourages us to use rosehip powder in obtaining functional food products. 


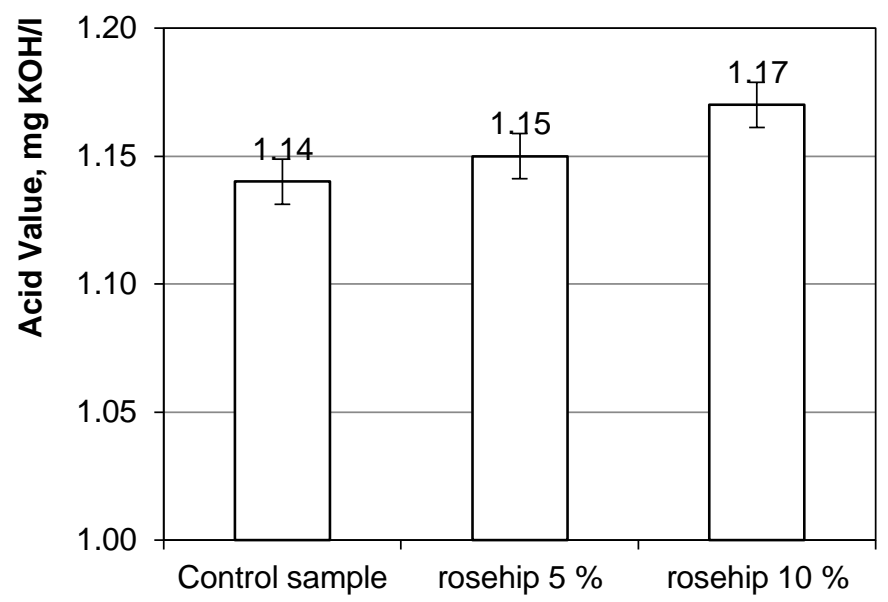

Figure 8. Acidity index in functional candies with rosehip powder, acidicy grade

\section{Sensory analysis of candy with the rosehip powder}

It was established that the sensory properties of the sample with 5\% rosehip powder are characterized by a good consistency, pleasant taste and fine odor.

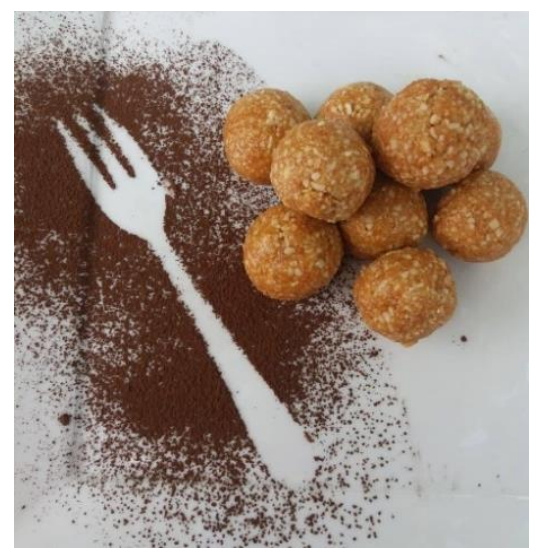

Figure 9. BIO candy with cashew and rosehip powder $(5 \%)$

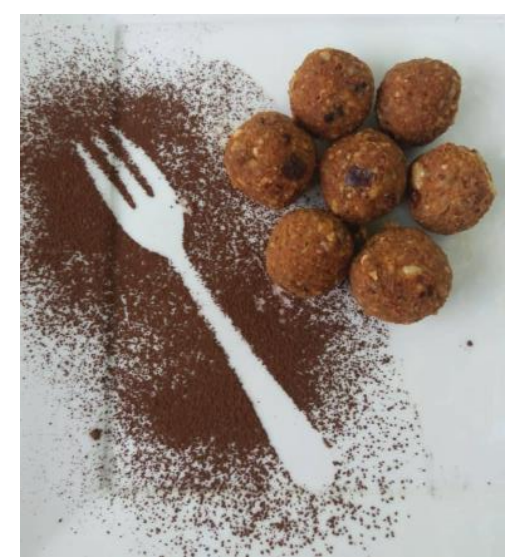

Figure 10. BIO candy with cashew and rosehip powder $(\mathbf{1 0 \%})$

According to the tasters' appreciation, this does not differ from the control sample which does not contain rosehip powder. Although, sample with $10 \%$ rosehip powder has a pleasing shape and odor, but tasters noted a bitter taste that is due to the increased powder content. The higher amount of powder, the more bitter taste intensifies. 


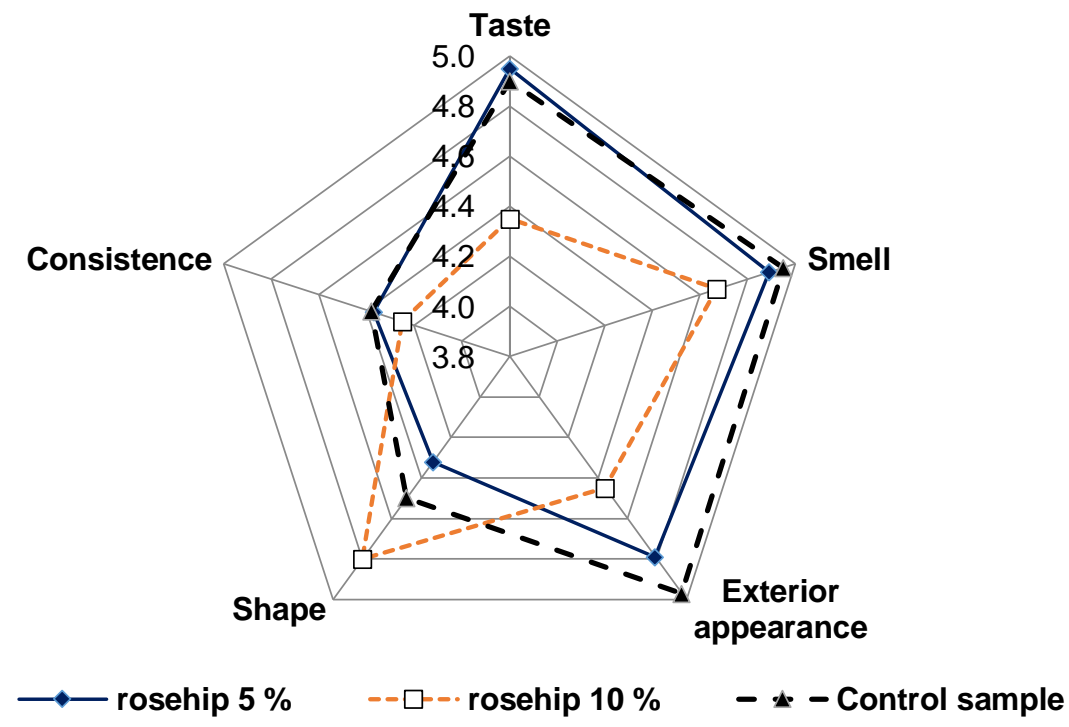

Figure 11. Sensory evaluation of functional candies with rosehip powder

As a result of the 5-point hedonic tests applying (Figure 11), it was established that the tested samples are positively appreciated and represent BIO products.

The use of rosehip powder presents a good possibility to increase the biological value of the product. Candies obtained on the base of rosehip powder represent a new product with functional properties, that do not induce the risk for consumers health.

\section{Conclusions}

The functional candies with rosehip powder have definite advantages in comparison to products obtained by the classical recipe. The rosehip high content of carotenoids (17.18 $\pm 0.01 \mathrm{mg} / \mathrm{L} \beta$-carotene; $18.13 \pm 0.03 \mathrm{mg} / \mathrm{L}$ lycopene; $18.02 \pm 0.02 \mathrm{mg} / \mathrm{L}$ zeaxanthin), enhanced antioxidant activity (up to $91 \%$ ) and the bioavailability of biologically active compounds, according to in Vitro simulation of gastrointestinal digestion, demonstrates the benefits of its use as natural antioxidants and colorants in the different foods. This fact allows the partial or total substitution of some synthetic preservatives with harmful action on human body, developing new technologies for functional food products obtaining. It was established that physico-chemical parameters of functional confenctionery products with rosa canina powder (1,14-1,17 mg KOH/1, 23-25 weight fraction of water,\%) correspond to normative documents. The sensory indices of the BIO candies are characterized by a good consistency, pleasant taste and fine odor and can be recommended for all categories of consumers.

\section{Acknolegements}

Authors gratefully thank the young researchers project 06/26.10.18A "Functional products obtained by using natural texture agents and carotenoids" for support. This research was partially supported by World Federation of Scientists. 


\section{References}

1. Kharazmi A (2008), Laboratory and preclinical studies on the anti-inflammatory and antioxidant properties of rosehip powder - Identification and characterization of the active component GOPO ${ }^{\circledR}$, Osteoarthritis and Cartilage, 16(1), pp. S5-S7.

2. Stralsio L., Alklint Ch., Olson M.E., Sjoholm I. (2003), Total folate content and retention in Rosehips (Rosa ssp) after Drying, J. Agric. Food Chem., 51, pp. 4291-4291.

3. Popovici V., Covaliov E., Capcanari T., Popovici C., Radu O. (2019), Evolution of total carotenoid content in food products enriched with rosehip (Rosa Canina) powder, Proceedings of the $8^{\text {th }}$ International Specialized Scientific and Practical Conference "Resource and Energy Saving Technologies of Production and Packing of Food Products as the Main Fundamentals of Their Competitiveness", National University of Food Technologies, Kyiv, Ukraine, September 12, 2019, p. 170.

4. Martirosyan D. (2011), Functional Foods and Chronic Diseases, Science and Practice. Food Science, p. 255.

5. Ciobanu C., Deseatnicov O., Sturza R., Curchi D. (2005), Procedeu de fabricare a produselor de panificație îmbogățite cu fier, Brevet de invenție $n r, M D-2895,31.10 .2005$, publicat BOPI Nr. 10/2005.

6. Sturza R. (2016), Principii moderne de analiză a alimentelor, Monografie, UTM, Chişinău.

7. Saykova I., Tylkowski B., Popovici C., Peev G. (2018), Extraction of phenolic and flavonoid compounds from solid wastes of grape seed oil production by cold pressing. Journal of Chemical Technology and Metallurgy, 53(2), pp. 177-190.

8. Popovici C. (2013), Soxhlet extraction and characterisation of natural compounds from walnut (Juglans regia L.) by-products, Ukrainian Food Journal, 2(2), pp. 328-336.

9. Šarolić M., Gugić M., Tuberoso C.I.G., Jerković I., Šuste M., Marijanović Z., Kuś P.M. (2014), Volatile Profile, Phytochemicals and Antioxidant Activity of Virgin Olive Oils from Croatian Autochthonous Varieties Mašnjača and Krvavica in Comparison with Italian Variety Leccino, Molecules, 19, pp. 881-895.

10. Tesfaye B., Abebaw A., Reddy M.U. Determination of Cholesterol and $\beta$-Carotene content in some selected Edible Oils, International Journal of Innovative Science and Research Technology, 2(7), pp. 14-18.

11. Biehler E., Mayer F., Hoffman L. (2009), Comparison of 3 Spectrophotometric Methods for carotenoid determination in frequentlz consumed fruits and vegetables, Journal of Food Science, pp. C1-C7.

12. Necula V. (2010), Analiza senzorială a alimentelor, Note de curs, pp. 2-4.

13. (1999), AOCS Official Method Cd 3d-63. AcidValue. Sampling and Analysis of commercial fats and oils.

14. Pavan V., Soriano Sancho R.A., Pastore G.M. (2014), The effect of in vitro digestion on the antioxidant activity of fruit extracts (Carica papaya, Artocarpus heterophillus and Annona marcgravii), LWT - Food Science and Technology, 59(2), Part 2, pp. 1247-1251.

15. Pakhomova I.V., Tkachenko A.S. (2015), Vplyv netradytsiinoi syrovyny na zberezhenist zhyrovmisnykh kondyterskykh vyrobiv, Tovaroznavchyi visnyk, 8. pp. 212-217.

16. Mariia Ianchyk, Oleksandra Niemirich (2016), Definition indicators of quality of the confectionery semi-finished product with powders from banana and carrot, Ukrainian Journal of Food Science, 4(1), pp. 76-84.

17. Ira Taneva, Petar Panayotov (2019), Analysis of vitamin $C$ enriched yoghurt by direct extraction of rosehip fruit in cow's milk during storage, Ukrainian Journal of Food Science, 7(1), pp. 61-69. 